\title{
Cognitive Somatic Symptoms and Stress among Parents with Intellectual and Developmental Disabilities Children
}

\author{
Norsuhaily Abu Bakar ${ }^{1}$, Jumadil Saputra ${ }^{2, *}$, Mohammad Shaban Al-smadi ${ }^{1}$, Mohd Hamidi Solahudin ${ }^{3}$, \\ Azni Yati Kamarudin ${ }^{4}$, Zulfa Izza Hashim ${ }^{1}$ \\ ${ }^{1}$ Faculty of Applied Social Science, Universiti Sultan Zainal Abidin, 21300 Kuala Nerus, Terengganu, Malaysia \\ ${ }^{2}$ Faculty of Business, Economics and Social Development, Universiti Malaysia Terengganu, \\ 21030 Kuala Nerus, Terengganu, Malaysia \\ ${ }^{3}$ Ministry of Education, Malaysia \\ ${ }^{4}$ Faculty of Education, Universiti Malaya, Malaysia
}

Received September 23, 2021; Revised October 25, 2021; Accepted November 29, 2021

\begin{abstract}
Cite This Paper in the following Citation Styles
(a): [1] Norsuhaily Abu Bakar, Jumadil Saputra, Mohammad Shaban Al-smadi, Mohd Hamidi Solahudin, Azni Yati Kamarudin, Zulfa Izza Hashim, "Cognitive Somatic Symptoms and Stress among Parents with Intellectual and Developmental Disabilities Children," Universal Journal of Public Health, Vol. 9, No. 6, pp. 378 - 384, 2021. DOI: 10.13189/ujph.2021.090604.
\end{abstract}

(b): Norsuhaily Abu Bakar, Jumadil Saputra, Mohammad Shaban Al-smadi, Mohd Hamidi Solahudin, Azni Yati Kamarudin, Zulfa Izza Hashim (2021). Cognitive Somatic Symptoms and Stress among Parents with Intellectual and Developmental Disabilities Children. Universal Journal of Public Health, 9(6), 378 - $384 . \quad$ DOI: 10.13189/ujph.2021.090604.

Copyright $\bigcirc 2021$ by authors, all rights reserved. Authors agree that this article remains permanently open access under the terms of the Creative Commons Attribution License 4.0 International License

\begin{abstract}
Adapting to the kids has been hinted at as having declining impacts as the disabled develops. Along these lines, this is an issue that could influence the whole family climate, particularly the moms' monetary state and enthusiastic equilibrium. The primary purpose of this paper is to examine the psychological, physical indications, and stress of emotional wellbeing for Parents of children with intellectual and developmental disabilities. This study used a quasi-experimental research design, with quantitative data being used to infer research conclusions. The results of CBTCF's Mann-Whitney demonstrated that CBTCF pre-experimental and pre-controlled moms, specifically of intellectually and developmentally disabled children had a pre-delivery. When examining the findings of all three distributions of questions, it became obvious that children in the experimental group did significantly better as those in the control group had parents of intellectual and developmentally disabled children. The Wilcoxon Signed Rank Test findings showed a major difference in the experimental group before, after, and after the system exposure, and the minimal difference for the control group was investigated. In children with intellectual and
\end{abstract}

developmental difficulties, the plan is also an effective therapy for behavioral problems with intellectual and developmental challenges that have behavioral issues.

Keywords Parent Intellectual, Developmental Disabilities Children, Somatic Cognitive Symptoms, Stress

\section{Introduction}

Stress is an enigma that affects everyone at some point in their lives. Every individual has had this experience since their initiation, as has humankind. Stress is one of the distinctive features of life and has been quite highlighted in its quality, so much so that it is common in expressive arts. The objective of increasing the closeness and integrity of human networks concerns is the complexity of human social, individual, and natural conditions, multiple and simultaneous cooperation between persons with difficulties, and various pressures involved in them [1]. Stress is a tendency of mental 
weight and tension in psychological science. Low stress, help, and even reliability can be desired. Stress can enhance bio-psychosocial wellbeing and encourage implementation in its positive structure. In addition, Positive pressure is also considered a vital element in inspiration, adjustment, and reactivity [2].

According to the World Health Organization (WHO), Worldwide, around 93 million (5 percent) children and adolescents are moderately or severely disabled. Furthermore, according to the Global Developmental Disability Research Collaborators, an estimated 53 million children under 5 are developmentally disabled, of which $95 \%$ live in low and middle-income countries.

The sign of the mental reaction to the children's condition formed the choices moms made for the benefit of their children. Mothers exhibited their mental reactions in a few structures. Initially, looking for intercessions and participating in rehearses that they saw could decidedly impact the ' 'children's circumstances and recuperation. Besides, in their impression of the standard of care, they gave their promise to mind, the compensations of mind, the nature of mind, adapting, trust later, and acknowledgment of the children's condition [3].

In any case, high nurturing pressure is a vital environmental danger variable. It has related to numerous troublesome outcomes, including gatekeeper hopelessness, intimate conflict, and less lucky actual well-being, less intriguing nurturing, and of most importance to the current examination, extended kid direct issues. Children with scholarly and formative disabilities are destined to grow up in families with high levels of nurturing pressure. Guardians of children with developmental delays typically report more nurturing pressure than guardians of normally developing children. Even though there is some confirmation that the pressure experienced by guardians of youngsters with developmental deferrals can be consistent, there is a stepped singular assortment toward it through an awesome range [3].

Adapting to children is expected to have diminishing effects as the handicapped's life span lengthens. Hence, this is an issue that could influence the whole family climate, particularly the moms' monetary state and enthusiastic equilibrium. Hence, researching the techniques for social-psychological coaching of these influenced youngsters in a more extensive point of view like strictness, relative resistance, and male to passionate female worry to consider the requirements of the kids with scholarly and formative incapacities is significant [4]-[9].

\section{Literature Review}

\subsection{Stress and Children with Intellectual and Developmental Disabilities}

A special needs child, often known as a child with intellectual and developmental problems, is a youngster who has been identified as requiring special attention and has needs that other children do not have. The state may designate this status to provide benefits and assistance for the child's health and development. Autism, Down syndrome, slow learners, cerebral palsy, and delayed deployment are examples of children with intellectual and developmental difficulties [10]. The Cognitive Behavioral Theory (CBT) is researched and posited as one of the most critically agreed models of depression and stress management. It is believed that negative and maladaptive thoughts accumulated by irrational or dysfunctional beliefs are the central phenomenon to stress. This research's decision to be discussed is due to its wide reachability and added holistic approach to depression. It has the vital incorporation of learning and behavioral ingredients towards cognitive theories [31]. It has recorded successes in the management of stress and depression evident from the past two centuries. The crises on stress management through depression were prominently described from the learning or cognitive-behavioral models [31]. These models unanimously approached the problem of the over-generalized response of depressed persons towards aversive conditions

Parents of kids with intellectual and developmental disabilities experience huge degrees of stress. Regardless of this, a few parents are yet ready to oversee viably and consider their youngsters. Adapting style, hopefulness, and social help have all been observed to be solid indicators of strength for parents of kids with disabilities. It furnishes professionals with another and proactive road for both appraisal and treatment of parental pressure. It is basic, considering how significant safeguarding individual assets are for these parents as they explore youngster care needs and every day bothers at the same time.

Understanding the components that form versatility inside parents advises clinical practice. It expands an expert's capacity to be a persuasive accomplice in assisting parents of children with intellectual and developmental disabilities to be successful careers [11]. 3.7 percent of Canadian children and teens have one or more disabilities, while $1.5 \%$ are serious to extremely severe In Saskatchewan, the figure for disability for children and young people is $3.9 \%$ [12].

Cerebral Palsy (CP) is the most widely recognized actual handicap in kids defenseless during childhood yet cause stayed obscure even get-togethers cases. The expression "Cerebral Palsy" portrays the issue of development and stance because of a deformity or sore of the juvenile mind [13]. Cerebral paralysis (CP) is a collection of issues that affect a person's ability to move and maintain balance and stance. In adolescence, $\mathrm{CP}$ is the most well-known engine handicap. The term "cerebral" refers to the cerebrum. The term "paralysis" refers to a lack of ability to use muscles. CP is caused by abnormal 
mental health or damage to the developing cerebrum, which affects a person's ability to regulate their muscles [13]-[15].

However, health-related related actual wellness is a significant advantage of a solid way of life due to its opposite relationship to Cardiovascular death. Physical exercise defined as any physiological movement resulting in energy expenditure and produced by skeletal muscles, is thought to contribute to physical fitness in a good way. However, in comparison to non-disabled adults, most people with impairments are less physically active. According to Durstine, Painter, Franklin, Morgan, Pitetti and Roberts [16] concept, inactivity causes a deconditioning cycle that leads to deterioration of many physiological systems. As a result, physical deterioration occurs, as does a decrease in physical activity. This deterioration may cause difficulty completing daily activities, developing symptoms such as pain, contractures, and exhaustion, and, as a result, a sedentary lifestyle.

\subsection{Parents of Children with Intellectual and Developmental Disabilities Report High Levels of Stress}

Although the incidence of stress differs among studies, enormous amounts of writing showed that previous studies found that pervasiveness ranged between $10-15 \%$ [3], [17]. While a recent study found that stress affects up to $20 \%$ of women in the first month after delivery, it also affects up to 500,000 mothers in the USA, the majority of whom are low-wage workers. In up to 20 percent of deliveries, stress occurs every year and is one of the most generally documented causes of suffering and mortality. Intellectual and developmental disabilities are two types of disabilities. Stress is not unique to the USA or western nations. Experts have discovered that $\mathrm{CP}$ stress occurs in various cultures, religions, sexual orientations, and countries, including Brazil, Cambodia, China, France, Germany, Malaysia, India, Korea, Malta, Mexico, Taiwan, and Turkey. According to Prakash, Patel, Hariohm, and Palisano [3], Concern about Cerebral Palsy, for example, is prevalent in 21.7 percent of developing countries. The commonness rate among cerebral palsy ladies in Iran was 22 percent, 23 percent in India, and 22 percent in Indonesia [18]. The reported prevalence among Chinese mothers was 32.9 percent [18], while the rate ranged from 16 to 35 percent in Zimbabwe.

\subsection{Causes of Stress in Mothers of Children with Intellectual and Developmental Disabilities}

Studies have attempted to recognize the various reasons for stress in mothers of children with intellectual and developmental disabilities. In an investigation by Terzi and Tan [19], the degree and severity of a child's handicap was listed as the main source of stress. Previous variables were identified and extended to focus solely on the child's behavior and severity. According to the findings, there is a clear link between mothers' stress management and the temperaments, degrees of deformity, and caregivers' attitudes toward children. It was discovered that a child's activity level is proportional to the tenderness and stress management of the caregiver [20]. It goes to the child's account, lowering the mother's overall load [21]. As a result, Terzi and Tan [19] claimed and supported the theory that a caregiver's attitude and management of a child's temperaments lessen overall stress and can anticipate the mother's stress. Their findings suggest that temperaments play a role in the mother's overall stress.

It was also discovered that the caregiver's flexibility, softness, and rigidity are proportionate to the total stress experienced by the mothers. As a result, a low-motivated and spirited caregiver directly impacts the proportionality of stress to mother comfort. As a result, it has been incorporated into various cognitive models as a critical component for acquiring a caring and compassionate caregiver for all children with intellectual and developmental problems. More guardians have also experienced their children's cultural dismissal because of seriousness and help in a disability. In many families, stresses are overseen because of not sharing the obligations of really focusing on a focused-on mother. Another excruciating stressor is the unsatisfactory social quality of uncommon necessities youngsters. A few perspectives incorporate not having any desire to impart sitting situations to the children, not utilizing similar social conveniences, cups, and eating utensils. This outcome is constant pressure on the mother and guardian [22].

\section{Materials and Methods}

\subsection{Design of the Study}

One of the most crucial aspects of conducting researchis the research design regardless of the subject of study. The current investigation was quantitative. This study takes a quantitative method, which entails collecting both quantitative and qualitative data sets and a series of analyses and data mixing at various stages to answer the research objectives [23]. The primary data-gathering instrument was a structured questionnaire derived and modified from previous research [24] on the appropriation of organizational adoption. The study tool made use of well-known measurement scales of earlier investigations [25]. The chosen items were modified to ensure that they would fit into the study's context.

\subsection{Instruments and Procedures for Data Collection}

In this study, data were collected using a pre/post/delay distribution of the questionnaire (quasi quasi-experimental study), primarily geared toward parents of children with 
intellectual and developmental disabilities. Merriam and Grenier [7] stated that the information gathered by figures is quantitative. However, according to Whitmore [8], the quantitative exploration technique is a strategy used to examine numerical data as the measurable strategy. This examination was led in Jordan and Malaysia, and the information was gathered through a self-regulated poll where the members were approached to finish the review all alone.

\subsection{Data Analysis}

In the analysis of the questionnaire data, the data were sampled from a Gaussian distribution, i.e., not normally distributions, and Man-Whitney and Wilcoxon non-parametric testing was used. A total of 70 respondents (e.g., pre and post-experimental and control groups) participated in this study. The researcher conducted data mining to ensure effective data representation before the actual data analysis. The frequency distribution was used to table the number of answers for each question and analyze each variable descriptively. Also, this study would be empirically testing the differences between mothers of children with intellectual and developmental disabilities for pre and post-experimental and control groups.

\section{Results}

\subsection{Between Group}

In the case of the pre-distribution experimental and control groups explicitly described by mothers of children with intellectual and developmental disabilities as reflected in the present study, Mann-Whitney (U) results from the CBTCF response in Table 1. The U-value is $33.67, \mathrm{z}$ is $-3.876, \mathrm{p}$ is 0.000 , and $\mathrm{r}$ is -0.466 . When the experimental and control groups' mean ranks were compared, it was clear that the experimental group's mean rank value (mean rank $=59.73$ ) was greater than the control group's mean rank value (mean rank $=44.87$ ). There was a statistically significant difference between the two groups because of this. The effect size of $r=-0.466$ indicated that the program had a medium to large influence on both the experimental and control CBTCF groups, meaning that the program had a significant impact on both groups.

Table 1. Between-Group among Pre-Experimental and Pre-Control CBTCF $(\mathrm{N}=70)$

\begin{tabular}{|c|c|c|c|c|c|}
\hline Program & $\begin{array}{c}\text { Mean } \\
\text { Rank }\end{array}$ & $\begin{array}{c}\text { U- } \\
\text { value }\end{array}$ & $\begin{array}{c}\text { Z- } \\
\text { value }\end{array}$ & $\begin{array}{c}\text { P- } \\
\text { value }\end{array}$ & $\begin{array}{c}\text { R- } \\
\text { value }\end{array}$ \\
\hline Pre-Experimental & 59.73 & 33.67 & -3.876 & 0.000 & $0.466^{* *}$ \\
\hline Pre-Control & 44.87 & & & & \\
\hline
\end{tabular}

Note: U-value (Mann-Whitney), P-value (positive value) R-value (rate value) and $Z$-value () and Significant at $* * P<0.05$
The results of the CBTCF are shown in Table 2 below. The experimental and control groups of the post-distribution were explicitly explained through the mothers of children with Cerebral Palsy represented in the current study. The experimental and control groups of the post-distribution showed a significant difference. The $\mathrm{U}$ value is 20.32 , the $z$ value is -6.541 , the $p$-value is 0.000 , and the $r$ value is -0.787 . When the experimental and control groups' mean ranks were compared, it was clear that the experimental group's mean rank value (mean rank $=83.55$ ) was greater than the control group's mean rank value (mean rank $=56.12$ ). There was a statistically significant difference between the two groups as a result of this. The program significantly influenced both the experimental and control groups of CBTCF, as evidenced by the large effect size of $\mathrm{r}=-0.787$.

Table 2. Between-Group among Post-Experimental and Post-Control CBTCF $(\mathrm{N}=70)$

\begin{tabular}{|c|c|c|c|c|c|}
\hline Program & $\begin{array}{c}\text { Mean } \\
\text { Rank }\end{array}$ & $\begin{array}{c}\text { U- } \\
\text { value }\end{array}$ & $\begin{array}{c}\text { Z- } \\
\text { value }\end{array}$ & $\begin{array}{c}\text { P- } \\
\text { value }\end{array}$ & $\begin{array}{c}\text { R- } \\
\text { value }\end{array}$ \\
\hline Post-Experimental & 83.55 & 20.32 & -6.541 & 0.000 & $0.787^{* *}$ \\
\hline Post-Control & 56.12 & & & & \\
\hline
\end{tabular}

Note: U-value (Mann-Whitney), P-value (positive value) R-value (rate value) and $\mathrm{Z}$-value () and Significant at $* * \mathrm{P}<0.05$

Similarly, Table 3 below shows the results of CBTCF. The experimental and control groups of the post-distribution explicitly explained through the mothers of children with Cerebral Palsy reflected in the current study demonstrated a substantial difference in the experimental and control groups of the post-distribution. The $\mathrm{U}$-value value is $12.45, \mathrm{z}$ value is -8.032 , $\mathrm{p}$-value is 0.000 , and $\mathrm{r}$ value is -0.967 . When the experimental and control groups' mean ranks were compared, it was clear that the experimental group's mean rank value (mean rank $=89.70$ ) was greater than the control group's mean rank value (mean rank $=63.44$ ). There was a statistically significant difference between the two groups as a result of this. The program substantially affected both the experimental and control groups of CBTCF, as evidenced by the effect size of $r=-0.967$.

Table 3. Between-Group among Delay-Experimental and Delay-Control CBTCF $(\mathrm{N}=70)$

\begin{tabular}{|c|c|c|c|c|c|}
\hline Program & $\begin{array}{c}\text { Mean } \\
\text { Rank }\end{array}$ & $\begin{array}{c}\text { U- } \\
\text { value }\end{array}$ & $\begin{array}{c}\text { Z- } \\
\text { value }\end{array}$ & $\begin{array}{c}\text { P- } \\
\text { value }\end{array}$ & $\begin{array}{c}\text { R- } \\
\text { value }\end{array}$ \\
\hline $\begin{array}{c}\text { Pre- } \\
\text { Experimental }\end{array}$ & 89.70 & 12.45 & -8.032 & 0.000 & $0.967^{* *}$ \\
\hline Post-Control & 63.44 & & & & \\
\hline
\end{tabular}

Note: U-value (Mann-Whitney), P-value (positive value) R-value (rate value) and $\mathrm{R}$-value () and Significant at ${ }^{*} \mathrm{P}<0.05$.

\subsection{Within Group}

Table 4 displays the Wilcoxon Signed-Rank test demonstrated a significant difference in the Pre and Post distribution of questionnaires in the CBTCF between the experimental and control groups $(\mathrm{T}=0.000, \mathrm{z}=-3.987, \mathrm{p}$ 
$=0.000, \mathrm{r}=-0.480) . \mathrm{CBTCF}$ exposure had a significant influence on mothers of children with intellectual and developmental disabilities in the associated task, according to the findings. The effect size of $r=-0.480$ indicates that the CBTCF strategy significantly increases the number of moms of children with intellectual and developmental disabilities. The CBTCF was well-known among palsy patients.

Table 4. Within-Group of the Experimental Group of CBTCF (N=70)

\begin{tabular}{|c|c|c|c|c|}
\hline Program & T-value & Z-value & P-value & R-value \\
\hline Before & 0.000 & -3.987 & 0.000 & $0.480^{* *}$ \\
\hline After & & & & \\
\hline
\end{tabular}

Note: U-value (Mann-Whitney), P-value (positive value) R-value (rate value) and $\mathrm{Z}$-value () and Significant at $* * \mathrm{P}<0.05$

In Table 5, the Wilcoxon Signed-Rank test revealed a significant difference between the pre and delayed questionnaire distribution experimental groups $(\mathrm{T}=0.000$, $\mathrm{z}=-5.543, \mathrm{p}=0.000, \mathrm{r}=-0.667)$. CBTCF exposure had a substantial impact on mothers of children with Cerebral Palsy in the associated task, according to the findings. The effect size of $r=-0.667$ is extremely strong, implying that the CBTCF strategy significantly enhanced CBTCF knowledge among moms of children with intellectual and developmental challenges.

Table 5. Within-Group of the Experimental Group of CBTCF (N=70)

\begin{tabular}{|c|c|c|c|c|}
\hline Program & T-value & Z-value & P-value & R-value \\
\hline Before & 0.000 & -5.543 & 0.000 & $0.667^{* *}$ \\
\hline Delay & & & & \\
\hline
\end{tabular}

Note: U-value (Mann-Whitney), P-value (positive value) R-value (rate value) and $\mathrm{Z}$-value () and Significant at **P $<0.05$

Table 6 further demonstrates that the Wilcoxon Signed-Rank test detects a significant difference between the post and delay distributions of the questionnaires $(\mathrm{T}=$ $0.000, z=-6.876, p=0.000, r=-0.828)$. In the associated task, the results demonstrated that CBTCF exposure significantly influenced mothers of children with intellectual and developmental challenges. The effect size of $r=-0.828$ indicates that the CBTCF strategy substantially enhanced CBTCF knowledge among moms of children with intellectual and developmental disabilities.

Table 6. Within-Group of the Experimental Group of CBTCF (N=70)

\begin{tabular}{|c|c|c|c|c|}
\hline Program & T-value & Z-value & P-value & R-value \\
\hline After & 0.000 & -6.876 & 0.000 & $0.828 * *$ \\
\hline Delay & & & & \\
\hline
\end{tabular}

Note: U-value (Mann-Whitney), P-value (positive value) R-value (rate value) and $\mathrm{Z}$-value () and Significant at $* * \mathrm{P}<0.05$

\section{Discussion}

The most important concerns identified with helping children with intellectual and developmental disabilities were health advancement and illness avoidance, therapeutic thought, recuperation organizations, and the use of assistive devices [26]. A key source of concern was the lack of attention. For parents and social workers who give support and recovery services, this concern is significant. The investigation's findings showed that reliable information was not available for parents in the natural environment and among national organizations [27] regarding the importance and explanation of specific necessities, clinical presentation, or conditions among public officials and suggested a lack of dominance among certain prosperity specialists.

Thus, prosperity experts are expressly required to strengthen available, government-funded counseling programs aimed at pediatric neurologic diseases by medium recovery specialists. These adolescents were 2 years of age, between 9 months and 14 years of age. Early research is viewed as enormous since it provides early and proper mediation instructions. Dieleman, Van Vlaenderen, Prinzie and De Pauw, [9] have demonstrated that early intervention for children with intellectual and developmental disabilities can enhance children's developmental outcomes. Also, it can improve parents' ability to address their children's needs, and increase individual family fulfillment.

The study's delayed outcome indicated concerns about the lack of attention they received throughout pregnancy and at work, which could have stopped their children from developing at a delayed or energized rate. In addition, individuals identified important stressors related to poor nutrition and postponed work [28]. Finally, financial worries were made regarding the lack of preparation and advice about the physical aspects of caring for their children, such as moving, arranging, mailing, and concerns for the children's and their security. Similarly, none of the moms I met expressed an interest in supportive gadgets that could help them maintain their physical wellbeing and boost their children's motor development. In terms of the guiding system, none of the children with intellectual and developmental disabilities attended school, and many of the parents were ignorant.

In this context, most individuals were experiencing financial hardships and were expected to rely on insecure and conflicting funding sources. The social part of the experiences of individuals centred around the weight that families and system people felt they accepted substantial mediations. Slander and separation from framework people were mentioned by few of them in their general populace. This study has demonstrated that parent-to-parent is an energetic personal development for the parent of intellectually and developmentally disabled children. The sufficiency of these undertakings was essentially proven because of this revelation. Parents who use Parent to Parent for non-emergency help benefit from interactions with other parents, according to the 
researchers, by feeling better prepared to adjust to their child's and family's situation, feeling more dynamically prepared to see their family and individual circumstances in an undeniably positive light, and assisting other parents in achieving basic goals. This study contradicted the assertions of Parent-to-Parent pioneers, who had countless stories of adults who became increasingly confident and convincing in regulating the environments in which their children were surrounded [29], [30]. Since their inception not long ago, Parent to Parent programs have mostly aimed to improve the lives of the middle and upper classes. In any event, in recent years, many of these organizations have begun to develop their support for lower-compensation parents and parents from ethnic minority social affairs. In addition, a parent from an ethnic minority group has begun to explain their child's personal growth.

Parents are expected to be useful to guardians with a poor profit margin because of this discovery [31]. The reasons why parent programs are beneficial or useless are explained in the specific area of this analysis. These revelations could be particularly valuable in assisting specialists in comprehending some of the challenges between master help and personal development. This outcome supported the hypothesis that shared lived experience and social interactions were important components of parent understanding. Parental personal development's distinct role is an unprecedented sort of subjectivity which is immediately obvious and subject to the shared nature of the experience. Regardless of the value that professionals provide to many huge companies, their language, point of view, and daily experience are vastly different from those of family members. Specialists may be able to provide information about specific families with whom they have worked. Nonetheless, when the connection is made by up close and personal interaction with people, the sociological inquiry is likely to be taken seriously.

\section{Conclusions}

In this study, parents of children with intellectual or developmental disabilities explored mental health's physical and cognitive stress. This study used a quasi-experimental methodology for research employing quantitative data to deduce research results. As a result of the tri-group experiments considered, it is evident that the experimental group was considerably better than those in the control group in which children with intellectual and developmental problems were parents. Furthermore, testing the differences between groups showed that the experimental group had a significant variation before, after, and after system exposure, while the insignificant differential for the control group was seen. In this test, the results showed a substantial difference between groups. In children with intellectual and developmental disabilities, the approach provides effective treatment for behavior problems.

\section{Acknowledgments}

We would like to thank Office of Terengganu Chief Minister, Universiti Sultan Zainal Abidin for supporting this research and publication. Also, Universiti Malaysia Terengganu, Universiti Malaya and Ministry of Education, Malaysia for these excellent collaboration work.

\section{REFERENCES}

[1] N. A. Bakar, N.A \& Radzali, "Factors and Job Satisfaction Dimension Among Academic Staffs of Public Universities," Int. J. Recent Technol. Eng., vol. 8, no. 2(3), pp. 427-430, 2019.

[2] A. Y. Bakar, N.A., Al Smadi, M.S, Kamarudin, "Management of Mental Health for Family with Special Needs," J. Adv. Res. Dyn. Control Syst., vol. 12, no. 7, pp. 1869-1874, 2020.

[3] N. Abu Bakar and I. Z. Baijuri, "Understanding Special Education 'Teachers' Perspectives on Professionalism in Educating Autistic Students," Int. J. Adv. Sci. Technol., vol. 29 , no. 1 , pp. $34-41,2020$.

[4] C. Jackson, A. Presanis, S. Conti, and D. De Angelis, "Value of information: Sensitivity analysis and research design in Bayesian evidence synthesis," J. Am. Stat. Assoc., 2019.

[5] N.A. Bakar, "Sociocultural Theory to Learning: 'Malaysia's Experiences," Man India, vol. 96, no. 12, pp. 5285-5304, 2016.

[6] N. A. Bakar, Alsmadi, M. S., \& Sulaiman I.M, "Effect of cognitive behavioral therapy for psychosis (cbtp) on mothers of youngsters with cerebral palsy," Univers. $J$. Public Heal., vol. 9, no. 3, pp. 113-119, 2021.

[7] S. B. Merriam and R. S. Grenier, Qualitative research in practice: Examples for discussion and analysis. John Wiley \& Sons, 2019.

[8] J. Whitmore, "The Hidden Curriculum and Associate Degree Nursing Instructors: A Basic Qualitative Study." Capella University, 2019.

[9] L. M. Dieleman, R. Van Vlaenderen, P. Prinzie, and S. S. W. De Pauw, "Parents' need-related experiences when raising an adolescent with cerebral palsy," Adv. Neurodev. Disord., vol. 3, no. 2, pp. 204-219, 2019.

[10] N. A. Bakar and M. S. Al-Smadi, "An Empirical Analysis of the Effectiveness of Behavioral Cognitive Mentoring: A Case Study of the Mothers of Children with Cerebral Palsy," 2019.

[11] F. Naeem, S. Arif, A. Asghar, and Z. Mahmood, "Psychosocial Stressors, Burnout and Mental Health Problems in Caregivers of Children with Cerebral Palsy," $J$. 
Postgrad. Med. Inst., vol. 32, no. 4, 2018.

[12] A. Kuschmann and A. Lowit, "Sentence stress in children with dysarthria and cerebral palsy," Int. J. Speech. Lang. Pathol., vol. 21, no. 4, pp. 336-346, 2019.

[13] Bakar, N. A. \& Al-Smadi, M.S. "Enhancing the affordability of cognitive behavioral therapy for children," Int. J. Psychosoc. Rehabil., vol. 24, no. 6, pp. 2218-2231, 2020.

[14] T. H. Patten, D. T., \& Hoekstra, U.S. Patent No. 10,117,028. Washington, DC: U.S.: Patent and Trademark Office, 2018.

[15] T. H. Marwick, "Stress echocardiography," Echocardiography, pp. 491-519, 2018.

[16] J. L. Durstine, P. Painter, B. A. Franklin, D. Morgan, K. H. Pitetti, and S. O. Roberts, "Physical activity for the chronically ill and disabled," Sport. Med., vol. 30, no. 3, pp. 207-219, 2000.

[17] H. Galloway, E. Newman, N. Miller, and C. Yuill, "Does parent stress predict the quality of life of children with a diagnosis of ADHD? A comparison of parent and child perspectives," J. Atten. Disord., vol. 23, no. 5, pp. 435-450, 2019.

[18] D. F. Parker, L. Carriere, H. Hebestreit, and O. Bar-Or, "Anaerobic endurance and peak muscle power in children with spastic cerebral palsy," Am. J. Dis. Child., vol. 146, no. 9, pp. 1069-1073, 1992.

[19] R. TeRzi and G. Tan, "Musculoskeletal system pain and related factors in mothers of children with cerebral palsy," Agri, vol. 28, no. 1, pp. 18-24, 2016.

[20] R. L. Naeye, E. C. Peters, M. Bartholomew, and J. R. Landis, "Origins of cerebral palsy," Am. J. Dis. Child., vol. 143 , no. 10 , pp. 1154-1161, 1989.

[21] A. Nagarkar, J. P. Sharma, S. K. Tandon, and P. Goutam, "The clinical profile of mentally retarded children in India and prevalence of depression in mothers of the mentally retarded," Indian J. Psychiatry, vol. 56, no. 2, p. 165, 2014.

[22] V. Prakash, A. M. Patel, K. Hariohm, and R. J. Palisano, "Higher levels of caregiver strain perceived by Indian mothers of children and young adults with cerebral palsy who have limited self-mobility," Phys. Occup. Ther. Pediatr., vol. 37, no. 1, pp. 64-73, 2017.

[23] M. Solaski, A. Majnemer, and M. Oskoui, "Contribution of socio-economic status on the prevalence of cerebral palsy: a systematic search and review," Dev. Med. Child Neurol., vol. 56, no. 11, pp. 1043-1051, 2014.

[24] N. Abu Bakar, M. S. Al-Smadi, and H. Mohd Pauzi, "Stress and Issues of Mental Health for Parent with Special Needs Children," Int. J. Adv. Sci. Technol., vol. 29, no. 7, pp. 471478, 2020.

[25] T. Krstić, L. Mihić, and I. Mihić, "Stress and resolution in mothers of children with cerebral palsy," Res. Dev. Disabil., vol. 47, pp. 135-143, 2015.

[26] J. Smyth, N. True, and J. Souto, "Effects of writing about traumatic experiences: The necessity for narrative structuring," J. Soc. Clin. Psychol., vol. 20, no. 2, pp. 161172,2001

[27] S. Cohen, "Social relationships and health," Am. Psychol., vol. 59, no. 8, p. 676, 2004

[28] A. Steptoe, "Invited review: The links between stress and illness," J. Psychosom. Res., vol. 35, no. 6, pp. 633-644, 1991.

[29] J. Flemmings, "Parental involvement: a study of 'parents' and 'teachers' experiences and perceptions in an urban charter elementary school"," 2013.

[30] J. Pulos, "Parent Expectations on the Postsecondary Environments of their Secondary-Age Children with Disabilities with High Support Needs: A Qualitative Exploration," 2020.

[31] J. C. Pfannenstiel, V. Seitz, and E. Zigler, "Promoting school readiness: The role of the Parents as Teachers program," NHSA Dialog A Res. J. early Interv. F., vol. 6, no. 1, pp. 71-86, 2003.

[32] A.E. Robertson, "Experience of Mental Health Diagnosis and Perceived Misdiagnosis in Autistic, Possibly Autistic and Non Autistic Adults". Psychology \& Counselling, 2018. https://doi.org/10.1177/1362361318818167 